TP Periodica Polytechnica Chemical Engineering

\author{
62(2), pp. 150-155, 2018 \\ https://doi.org/10.3311/PPch.11430 \\ Creative Commons Attribution (1)
}

RESEARCH ARTICLE

\section{Characterization of Ion Exchange Material Behavior under Pressure Simulating Electro-Membrane Cell Conditions}

\author{
Ladislav Zich ${ }^{1}$, Natália Václavíková ${ }^{*}$
}

Received 28 August 2017; accepted after revision 16 November 2017

\begin{abstract}
Goal of this work was to measure dimensional changes of ion-exchange membranes and resins used in electrodialysis (ED) or electrodeionization (EDI) devices under the applied pressure and temperatures up to $60{ }^{\circ} \mathrm{C}$ in order to describe their behavior in real conditions of these processes. Regarding ion exchange resins, measurements of their compressibility were carried out with samples of gel strongly basic and strongly acidic pure resins, their mixture and macroporous strongly acidic resin. In case of ion exchange membranes, their thickness changes under the influence of pressure and temperature were measured and long-term experiments were performed with the maximal applied pressure. To obtain a complete view, ED spacer frame foil properties were also examined in longterm experiments. For each experiment, the unique work methodology and measurement apparatus was proposed. It was found that each resin exhibited specific behavior under applied pressure and temperature. Furthermore, the important impact of temperature changes on ion exchange membranes and ED spacer foils was observed, and then, it was examined under the conditions of pressure load similar to that in real ED device. This work confirms that the research of mechanical properties of ion exchange materials has a great importance, mainly if it simulates real conditions in industrial ED and EDI modules. It can help in designing new or improved module components taking into account expected temperature or pressure changes of ion exchange materials.
\end{abstract}

\section{Keywords}

compressibility, ion exchange resin, ion exchange membrane, electrodialysis, electrodeionization

\section{Introduction}

Electrodialysis (ED) and electrodeionization (EDI) are electrochemical separation processes using direct current electric field to separate charged particles from solutions. ED process is performed using the device called electrodialyzer or electro-membrane module that is composed of two electrodes and membrane stack which contains alternatively arranged cation and anion exchange membranes separated by plastic spacers. Whole stack is tightened between massive tightening desks. Basic principles of ED are well established and were explained e.g. in [1]. EDI is separation, purification and concentration method as well and it uses the concept of electro-membrane module as described above, but at least diluate chambers (chambers in which the solution is desalinated) are filled by ion exchange resin in order to minimize concentration polarization phenomenon and to be able to purify low-conductivity water. Actually, it is a hybrid technology joining together mechanisms of electrodialysis and ion exchange. Its basic principles were described in detail e.g. in [2].

Ion exchange resins (IER) are cross-linked polymers that carry fixed functional groups. IERs may be classified into cationic or anionic, acidic or basic, weak or strong depending on their polymer matrix and functional groups. Properties and performance of resins are strongly affected by matrix type and degree of crosslinking (\% divinylbenzene). According to polymer structure of the resin, gel or macroporous resins can be recognized. Compared to gel IERs, macroporous are highly crosslinked, generally tougher and more resistant to mechanical or chemical degradation. However, the rate of ion exchange is usually faster when using gel forms. Among physicochemical characteristics of IERs, type of functional groups, ionic form, water content, ion exchange capacity, swelling, chemical and thermal stability are the most important. The other properties include particle size, uniformity coefficient, density, sphericity or percent of whole beads $[4,5]$. Ion exchange membranes (IEM) are classified into cation exchange membranes (CEM) and anion exchange membranes (AEM) according to their ionic groups. AEMs have positively charged ionic groups wile CEMs carry negatively charged groups. Furthermore, according to their structure, IEMs can be divided into homogeneous and
${ }^{1}$ Department of Membrane Processes, MemBrain s.r.o,

Pod Vinicí 87, 47127 Stráž pod Ralskem, Czech Republic

${ }^{*}$ Corresponding author, e-mail: natalia.vaclavikova@membrain.cz 
heterogeneous. In homogeneous membranes, charged groups are bonded to membrane matrix chemically while in heterogeneous membranes they are physically mixed with it [3]. IEMs are essential part of electro-membrane modules and it is necessary to know their electrochemical and physicochemical properties. Therefore, membrane characterization commonly includes determination of ion exchange capacity, swelling properties, porous structure, electrical conductivity, transport numbers of ions, selectivity, diffusion permeability, hydraulic permeability, chemical and thermal stability or voltammetry curves [6, 7]. Moreover, IEMs should exhibit flatness and uniformity of properties, good durability in use, mechanical strength, toughness and good dimensional stability [8].

Dimensional changes, mechanical stability or water uptake of ion exchange materials were most often examined in association with exposure to some chemicals and at different temperatures. Sata et al. examined mechanical stability of AEMs in concentrated sodium hydroxide solution at temperatures up to $75^{\circ} \mathrm{C}$ [9]. Amel et al. investigated differences in water uptake and dimensional swelling between AEMs in $\mathrm{Cl}^{-}$and $\mathrm{HCO}_{3}^{-}$ ionic form in the range of temperatures $25-80{ }^{\circ} \mathrm{C}$ [10]. Lin et al. characterized AEM with enhanced resistance to dimensional changes in terms of water uptake, swelling ratio, tensile strength and elongation at break in the temperature range of 30 $-80{ }^{\circ} \mathrm{C}$ [11]. Laín and Barragán studied swelling properties of four AEMs (including both heterogeneous and homogeneous) in pure water, various mixtures of water and alcohols and mixtures of water, alcohol and alkali hydroxide [12]. Svoboda et al. examined the effect of salt concentration on heterogeneous CEM swelling and found out that it is one of the major factors influencing this feature. Moreover, they managed to find empirical equation for estimating membrane volumetric changes in different salt solutions [13]. However, according to authors' best knowledge, mechanical properties of ion exchange materials have never been investigated at pressure and temperature conditions simulating industrial electro-membrane module. From the point of view of design and construction of industrial modules, such knowledge is crucial as it can help to predict the behavior of ion exchange materials after membrane stack assembling and during its performance and to adjust each component appropriately. This article describes compressibility of different ion exchange resins and membranes at various process conditions measured by several methods to evaluate the one that is most accurate in order to be able to predict their behavior when incorporated in electrodialysis or electrodeionization module.

\section{Materials and methods \\ 2.1 Materials}

Four ion exchange resin samples were tested - anion exchange resin Diaion ${ }^{\text {TM }}$ SA10A (Mitsubishi Chemicals Europe $\mathrm{GmbH}$ ), cation exchange resin Diaion ${ }^{\mathrm{TM}}$ SK1B (Mitsubishi Chemicals Europe $\mathrm{GmbH}$ ), their mixture in the volumetric ratio
SK1B:SA10A $=55: 45$, and cation exchange resin Purolite C 160 (Purolite Ltd). These resin types were selected as they are typically used as a filling of EDI module working chambers. Gel resins are used in diluate or concentrate chambers either in layers or as mixed beds. Macroporous cation exchangers are often used in the chambers of electrode solution. The characteristic properties of pure resins are listed in Table 1.

Table 1 Characteristic ion exchange resin properties (provided by manufacturer)

\begin{tabular}{|c|c|c|c|}
\hline Type & $\begin{array}{l}\text { Diaion }^{\mathrm{TM}} \text { SA10A } \\
\text { Strongly basic }\end{array}$ & $\begin{array}{l}\text { Diaion }^{\mathrm{TM}} \text { SK1B } \\
\text { Strongly acidic }\end{array}$ & $\begin{array}{l}\text { Purolite C160 } \\
\text { Strongly acidic }\end{array}$ \\
\hline Functional group & $\begin{array}{l}\text { Quaternary } \\
\text { ammonium }\end{array}$ & Sulfonic acid & Sulfonic acid \\
\hline Polymer structure & Gel & Gel & Macroporous \\
\hline $\begin{array}{l}\text { Moisture } \\
\text { retention [\%] }\end{array}$ & $43-47$ & $43-50$ & $35-40$ \\
\hline $\begin{array}{l}\text { Particle size } \\
\text { range }[\mu \mathrm{m}]\end{array}$ & $300-1180$ & $300-1180$ & $300-1200$ \\
\hline
\end{tabular}

Heterogeneous ion exchange membranes Ralex ${ }^{\circledR}$ CM-PES and Ralex ${ }^{\circledR}$ AMH-PES (MEGA a.s., Stráž pod Ralskem, Czech Republic) were used in experiments. Their properties are presented in Table 2. In long-term experiments, typical spacer frame materials were used to compare their mechanical properties with IEMs. Spacer frame materials were made in MemBrain s.r.o. (Stráž pod Ralskem, Czech Republic) from commercially available resins Versify ${ }^{\mathrm{TM}} 2000$ (The Dow Chemical Company, USA) and Bralen FB 2-30 (Slovnaft Petrochemicals, Slovak Republic) whose properties are summarized in Table 3. Thickness of both spacer foils was $0.8 \mathrm{~mm}$ (spacer thickness commonly used in ED modules).

Table 2 Important properties of ion exchange membranes (provided by manufacturer)

\begin{tabular}{lll}
\hline & Ralex ${ }^{\circledR}$ AMH-PES & Ralex ${ }^{\circledR}$ CM-PES \\
\hline Functional group & $\begin{array}{l}\text { Quaternary } \\
\text { ammonium }\end{array}$ & Sulfonic acid \\
Ionic form & $\mathrm{Cl}^{-}$ & $\mathrm{Na}^{+}$ \\
Binding agent & $\mathrm{PE}$ & $\mathrm{PE}$ \\
Reinforcing fabric & $\mathrm{PES}$ & $\mathrm{PES}$ \\
Thickness in dry state $[\mathrm{mm}]$ & $<0.45$ & $<0.45$ \\
Thickness in swollen state $[\mathrm{mm}]$ & $<0.75$ & $<0.70$ \\
\hline
\end{tabular}

Table 3 Properties of resins used for spacer frame foils manufacturing (provided by manufacturer)

\begin{tabular}{lll}
\hline & Versify $^{\text {TM }}$ 2000 & Bralen FB 2-30 \\
\hline Material & PP & PE \\
Density $\left[\mathrm{g} \mathrm{cm}^{-3}\right]$ & 0.888 & 0.919 \\
Shore D hardness & 54 & 41 \\
Vicat softening temperature $\left[{ }^{\circ} \mathrm{C}\right]$ & 94 & 96 \\
\hline
\end{tabular}




\subsection{Measurement of ion exchange resin compressibility}

The apparatus for measurements of ion exchange resin deformation resistance was composed of steel tubular cylinder (outer diameter $50 \mathrm{~mm}$, inner diameter $30 \mathrm{~mm}$, and height $200 \mathrm{~mm}$ ) and steel plunger. Weighted ion exchange resin sample was placed into the cylinder and then the plunger was installed there. During the experiment, the pressure up to $11.7 \mathrm{~kg} \mathrm{~cm}^{-2}$ was applied on the plunger and the change of its position in the cylinder was recorded (Fig. 1). Pressure range was selected taking into account pressures which are commonly used in industrial EDI stacks produced by MEGA a.s. (Stráž pod Ralskem, Czech Republic). The reference measurement was carried out with the dry resins (below $6 \%$ of moisture) at the temperature of $25^{\circ} \mathrm{C}$. Then, the other measurements were done with swollen resins at the temperatures $25^{\circ} \mathrm{C}, 40^{\circ} \mathrm{C}$ and $60{ }^{\circ} \mathrm{C}$. All measurements were performed in triplicates.

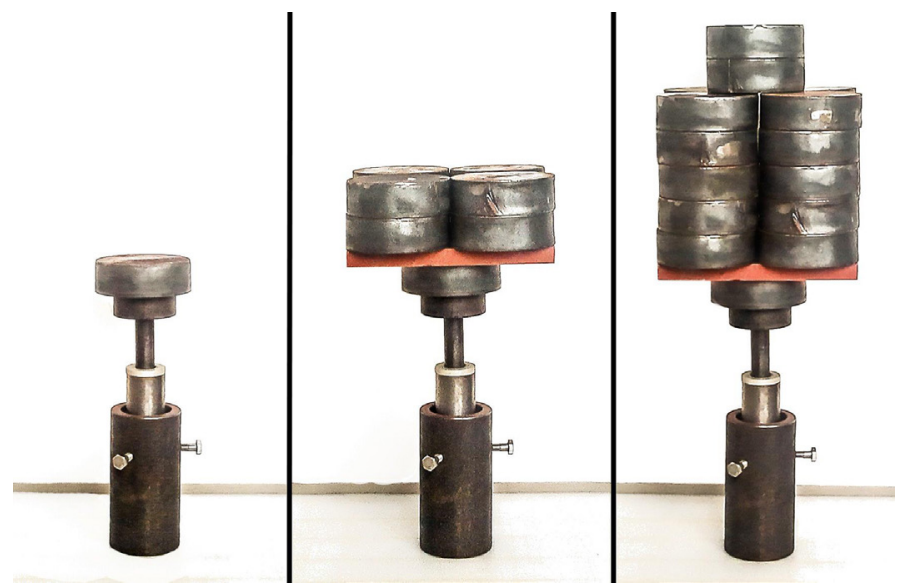

Fig. 1 Arrangement for the measurement of ion exchange resin deformation resistance

\subsection{Measurement of ion exchange membranes compressibility}

The stack of ten round membrane samples with the diameter of $19 \mathrm{~mm}$ was placed between two metal decks (Fig. 2) and the pressure up to $4.36 \mathrm{~kg} \mathrm{~cm}^{-2}$ was applied on the samples. Pressure range was selected taking into account pressures which are commonly used in industrial ED stacks produced by MEGA a.s. (Stráž pod Ralskem, Czech Republic). Desired pressure was achieved in such way that metal blocks with a defined weight were placed on the top of the upper deck (taking into account the weight of the upper deck as well). Experiments were carried out in water with the temperature $25^{\circ} \mathrm{C}, 40^{\circ} \mathrm{C}$ or $60^{\circ} \mathrm{C}$ and three different methods were tested to obtain the best description of membrane behavior in the membrane stack. The change of the gap thickness between decks $\Delta$ h (Fig. 2) was measured using caliper and all measurements were done in triplicates.

Method 1

Membrane samples were placed between decks and put into water with the temperature $25^{\circ} \mathrm{C}$. The reference gap thickness was measured and then the applied pressure was increasing and the corresponding gap thickness was recorded. At the highest pressure $\left(4.36 \mathrm{~kg} \mathrm{~cm}^{-2}\right)$, the water was heated to $40{ }^{\circ} \mathrm{C}$ and then to $60{ }^{\circ} \mathrm{C}$. This method should represent the conditions of ED or EDI stack assembling in the best way.

\section{Method 2}

Membrane samples were placed between decks and put into water with the temperature $25^{\circ} \mathrm{C}$. After reference gap thickness measurement at $25{ }^{\circ} \mathrm{C}$, the pressure of $4.36 \mathrm{~kg} \mathrm{~cm}^{-2}$ was applied. Then, the pressure was removed, the temperature was increased to $40{ }^{\circ} \mathrm{C}$, and the pressure was applied again. The same procedure was repeated when the temperature was increased to $60{ }^{\circ} \mathrm{C}$.

\section{Method 3}

The membrane samples were put into the water with desired temperature $\left(25^{\circ} \mathrm{C}, 40^{\circ} \mathrm{C}\right.$ or $\left.60^{\circ} \mathrm{C}\right)$ and let there for at least 30 minutes. Then, they were put between preheated decks into the water of appropriate temperature. The pressure was applied and the corresponding gap thickness was measured.

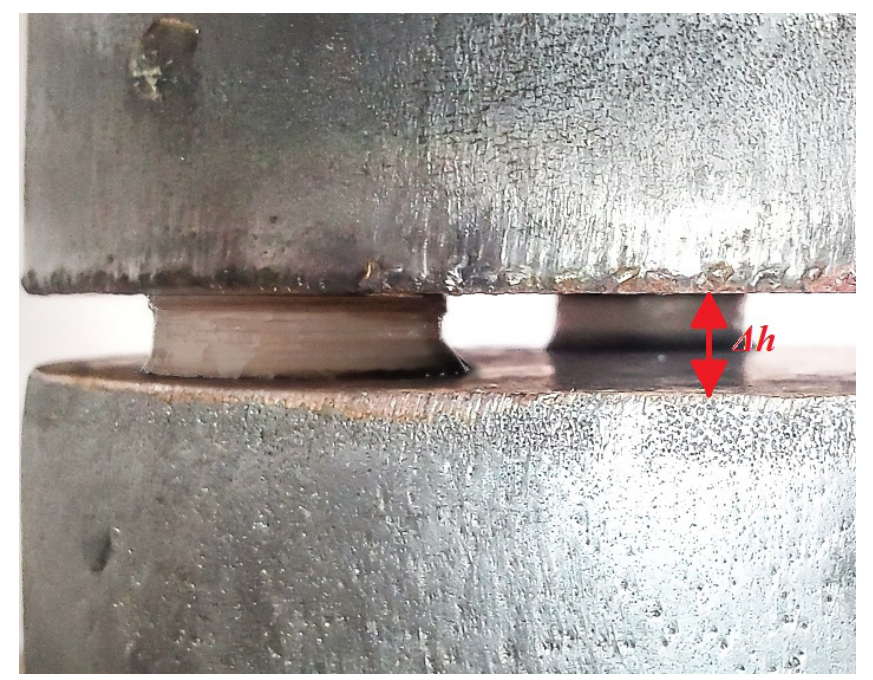

Fig. 2 Arrangement for the measurement of ion exchange membrane dimensional changes (stack of ten round membrane samples placed between two metal decks)

\subsection{Long-term experiments}

Membrane and spacer frame foil samples (stacks of ten round pieces) were placed between two decks into water of ambient temperature and the pressure of $4.36 \mathrm{~kg} \mathrm{~cm}^{-2}$ was applied. The initial gap thickness was measured and then, this parameter was recorded regularly in time. The experiment duration was 2000 hours.

\section{Results and discussion \\ 3.1 lon exchange resins}

The volumetric change $\Delta V[\%]$ was calculated according to Eq. (1):

$$
\Delta V=\frac{V_{0}-V_{f}}{V_{0}} 100 \%
$$


where $V_{0}$ is the reference resin volume $\left(25^{\circ} \mathrm{C}\right.$, no applied pressure, given moisture content) and $V_{f}$ is the resin volume at the same moisture content, given temperature and applied pressure.

The results of measurements of ion exchange resin deformation resistance are summarized in Tables 4 and 5. As expected, volume changes of dry resins (less than $6 \%$ of moisture) were negligible. While swelling, the resin volume change could achieve up to $140 \%$, so that the space for deformation is much broader and water can be displaced from resin grains. However, the initial state (volume of the dry resin) was not achieved even at the highest applied pressure $11.7 \mathrm{~kg} \mathrm{~cm}^{-2}$ so that some moisture always stayed in grains. This fact is important in terms of good electrical conductivity of resin beads in EDI chambers, as water content is the decisive factor influencing it. At the temperature $40^{\circ} \mathrm{C}$ or $60^{\circ} \mathrm{C}$, the volume changes were more significant than those at $25^{\circ} \mathrm{C}$ (Table 5) as elasticity of material increased. But in the case of pure Diaion ${ }^{\mathrm{TM}}$ resins, the volume changes at $40{ }^{\circ} \mathrm{C}$ and $60{ }^{\circ} \mathrm{C}$ were very similar, so the dependence on the temperature is obviously non-linear and reaches the plateau. Regarding pure resins, volume changes were the smallest in the case of macroporous cation exchange resin Purolite C 160, and the largest in the case of gel cation exchange resin Diaion ${ }^{\mathrm{TM}}$ SA10A. This can be explained by differences between polymer structure of macroporous and gel resins, as macroporous resins are generally highly crosslinked and therefore they are usually tougher and more mechanically resistant [5]. In Figs. 3-5, the dependence of resin volume changes on applied pressure is depicted at different temperatures. From the technological point of view, the most interesting are the data obtained with the mixture of Diaion ${ }^{\mathrm{TM}}$ resins. Very often, the mixed beds of cation and anion exchange resin are used as the filling of diluate chambers in continuous EDI modules as the resin regeneration ability is better due to intensive generation of $\mathrm{H}^{+}$and $\mathrm{OH}^{-}$ions at bipolar interfaces [14]. The volume changes at different temperatures were the most pronounced just for the resin mixture. Interestingly, the temperature dependence of volume changes did not reach the plateau up to $60^{\circ} \mathrm{C}$. The possible explanation of the fact that resin mixture exhibited the highest volume changes is that the particle size of cation and anion exchange resin was different (manufacturer provides quite broad particle size range $300-1180 \mu \mathrm{m}$ for both) and when pressure was applied, smaller particles filled the gaps between the larger ones so that higher compressibility was observed.

Table 4 Volume changes of resins in the dry state at the applied pressure $11.7 \mathrm{~kg} \mathrm{~cm}^{-2}$

\begin{tabular}{ll}
\hline Resin type & $\Delta \mathrm{V}[\%]$ \\
\hline Diaion $^{\mathrm{TM}}$ SA10A & $<0.5$ \\
Diaion $^{\mathrm{TM}}$ SK1B & $<0.5$ \\
Diaion $^{\mathrm{TM}}$ mixed bed & $<1.0$ \\
Purolite C 160 & $<0.5$ \\
\hline
\end{tabular}

Table 5 Volume changes of resins in the fully swollen state at the applied pressure $11.7 \mathrm{~kg} \mathrm{~cm}^{-2}$ and different temperatures

\begin{tabular}{llll}
\hline Resin type & $\Delta \mathrm{V}\left(25^{\circ} \mathrm{C}\right)[\%]$ & $\Delta \mathrm{V}\left(40^{\circ} \mathrm{C}\right)[\%]$ & $\Delta \mathrm{V}\left(60^{\circ} \mathrm{C}\right)[\%]$ \\
\hline Diaion $^{\mathrm{TM}} \mathrm{S} A 10 \mathrm{~A}$ & $12.8 \pm 1.6$ & $14.5 \pm 2.2$ & $15.6 \pm 0.8$ \\
Diaion $^{\mathrm{TM}} \mathrm{SK} 1 \mathrm{~B}$ & $11.3 \pm 0.8$ & $13.3 \pm 2.0$ & $12.5 \pm 0.4$ \\
Diaion $^{\mathrm{TM}}$ mixed bed & $14.1 \pm 1.2$ & $16.9 \pm 1.5$ & $19.2 \pm 0.7$ \\
Purolite C 160 & $6.5 \pm 0.1$ & $7.3 \pm 0.9$ & $6.7 \pm 0.4$ \\
\hline
\end{tabular}

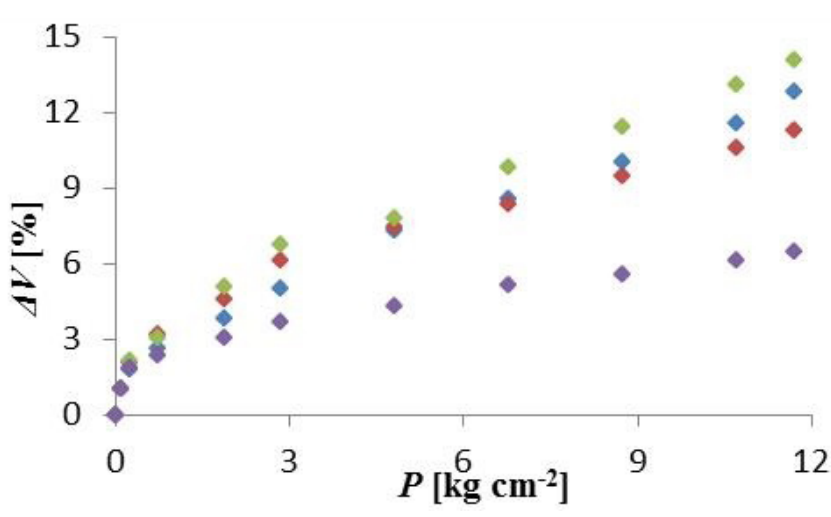

Fig. 3 Dependence of resin volume changes on applied pressure measured at the temperature $25^{\circ} \mathrm{C}\left(\right.$ Diaion $^{\mathrm{TM}} \mathrm{SA} 10 \mathrm{~A}$, Diaion $^{\mathrm{TM}} \mathrm{SK} 1 \mathrm{~B}$, Diaion $^{\mathrm{TM}}$ mixed bed, $\diamond$ Purolite C160)

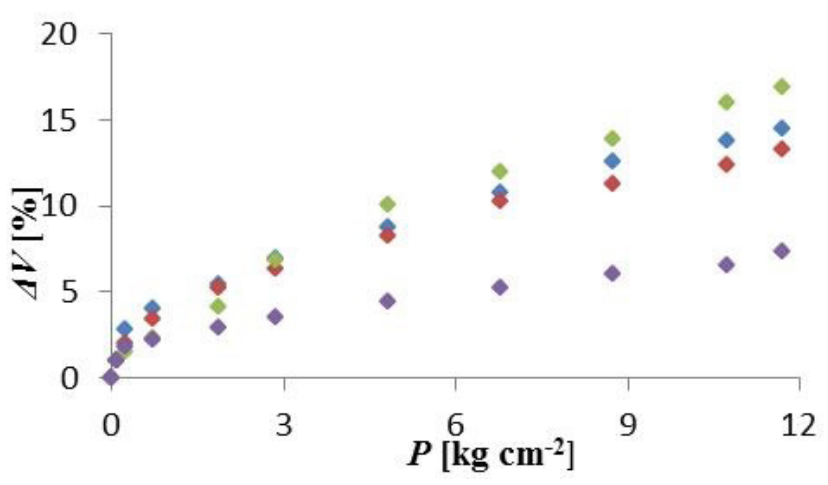

Fig. 4 Dependence of resin volume changes on applied pressure measured at the temperature $40{ }^{\circ} \mathrm{C}\left(\diamond\right.$ Diaion $^{\mathrm{TM}} \mathrm{SA} 10 \mathrm{~A}$, Diaion $^{\mathrm{TM}} \mathrm{SK} 1 \mathrm{~B}, \diamond$ Diaion $^{\mathrm{TM}}$ mixed bed, Purolite C160)

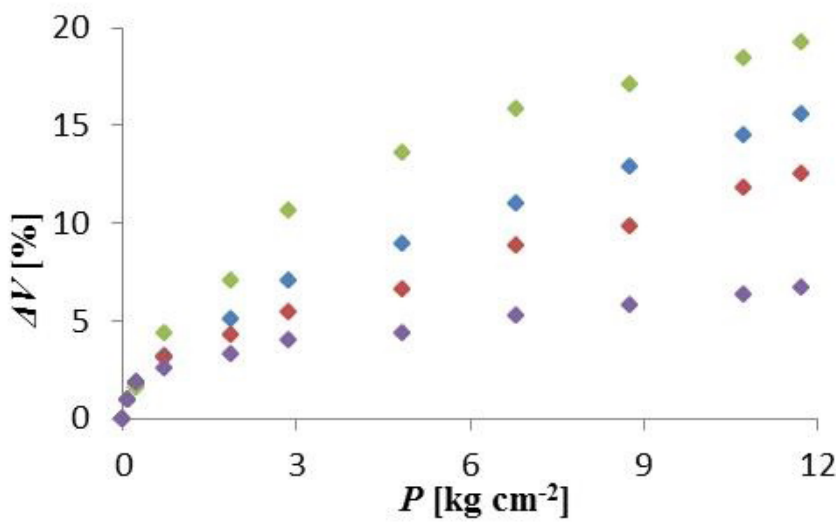

Fig. 5 Dependence of resin volume changes on applied pressure measured at the temperature $60{ }^{\circ} \mathrm{C}\left(\right.$ Diaion $^{\mathrm{TM}} \mathrm{SA} 10 \mathrm{~A}$, Diaion $^{\mathrm{TM}} \mathrm{SK} 1 \mathrm{~B}$, Diaion $^{\mathrm{TM}}$ mixed bed, $\diamond$ Purolite C160) 


\section{2 lon exchange membranes}

The membrane thickness change $\Delta h$ was calculated using Eq. (2):

$$
\Delta h=\frac{h_{0}-h_{f}}{h_{0}} 100 \%
$$

where $h_{0}$ is the membrane reference thickness $\left(25^{\circ} \mathrm{C}\right.$, no applied pressure) and $h_{f}$ is the membrane thickness at applied pressure and given temperature.

In Table 6, there are listed membrane thickness changes measured at different temperatures and by three different methods. Also in the case of ion exchange membranes, the temperature dependence was obvious as thickness changes were increasing with temperature. The difference between three used methods was visible only in the case of cation exchange membrane at higher temperatures but the variance was not significant. This data can help to predict membranes behavior during ED or EDI performance, when the temperature in the stack increases due to electric current and then decreases again e.g. at the beginning of another batch processing or during cleaning-in-place. In such case, membrane thickness decreases as well, tightness of the stack deteriorates and risk of external leakages arises. Figs. 6 and 7 show the pressure dependence of IEM thickness changes at different temperatures measured by Method 3, as only this method shows behavior of thickness changes in the whole measured range of applied pressure at higher temperatures (Method 1 and Method 2 provides only one measured thickness change value at the temperature of $40{ }^{\circ} \mathrm{C}$ or $60^{\circ} \mathrm{C}$, at the pressure of $4.36 \mathrm{~kg} \mathrm{~cm}^{-2}$ ).

\subsection{Long-term experiments}

The membrane thickness change in the long-term experiments $\Delta h_{L T}$ was calculated using Eq. (3):

$$
\Delta h_{L T}=\frac{h_{t=0}-h_{t}}{h_{t=0}} 100 \%
$$

where $h_{t=0}$ is the thickness of the membrane at the beginning of the test (applied pressure $4.36 \mathrm{~kg} \mathrm{~cm}^{-2}$ ) and $h_{t}$ is the membrane thickness in certain time.

Fig. 8 represents the thickness change of ion exchange membranes and spacer frame foils (Bralen or Versify ${ }^{\mathrm{TM}}$ ) exposed to constant pressure of $4.36 \mathrm{~kg} \mathrm{~cm}^{-2}$ in time. It is visible that thickness changes were the most significant in the beginning of experiment. In the case of membranes, the sharp increase occurred in the first 200 hours. After this time, the increase was slower and after 1250 hours the membrane thickness seemed to be almost stable. Higher changes were observable for AEM than for CEM. Also the dependence shape was different.

There were no significant differences in the behavior of two kinds of spacer frame foils. The dependence shape was similar for both Bralen and Versify ${ }^{\mathrm{TM}}$ foil. In the first 550 hours, Bralen foil was deformed more strongly. After 800 hours, the thickness
Table 6 Membrane thickness changes at the applied pressure $4.36 \mathrm{~kg} \mathrm{~cm}^{-2}$ and different temperatures measured by various methods

\begin{tabular}{llll}
\hline & $\Delta h\left(25^{\circ} \mathrm{C}\right)[\%]$ & $\Delta h\left(40{ }^{\circ} \mathrm{C}\right)[\%]$ & $\Delta h\left(60{ }^{\circ} \mathrm{C}\right)[\%]$ \\
\hline Method 1 & & & \\
Ralex® AMH-PES & $5.9 \pm 0.2$ & $6.5 \pm 0.3$ & $7.9 \pm 0.3$ \\
Ralex® CM-PES & $8.4 \pm 0.6$ & $9.4 \pm 0.6$ & $9.9 \pm 0.7$ \\
\hline Method 2 & & & \\
Ralex® AMH-PES & $5.4 \pm 0.3$ & $6.6 \pm 0.2$ & $7.6 \pm 0.3$ \\
Ralex® CM-PES & $8.6 \pm 0.2$ & $9.6 \pm 0.4$ & $10.8 \pm 0.7$ \\
\hline Method 3 & & & \\
Ralex ${ }^{\circledR}$ AMH-PES & $5.6 \pm 0.1$ & $6.5 \pm 0.2$ & $7.2 \pm 0.2$ \\
Ralex ${ }^{\circledR}$ CM-PES & $8.5 \pm 0.5$ & $10.7 \pm 0.7$ & $11.4 \pm 0.6$ \\
\hline
\end{tabular}

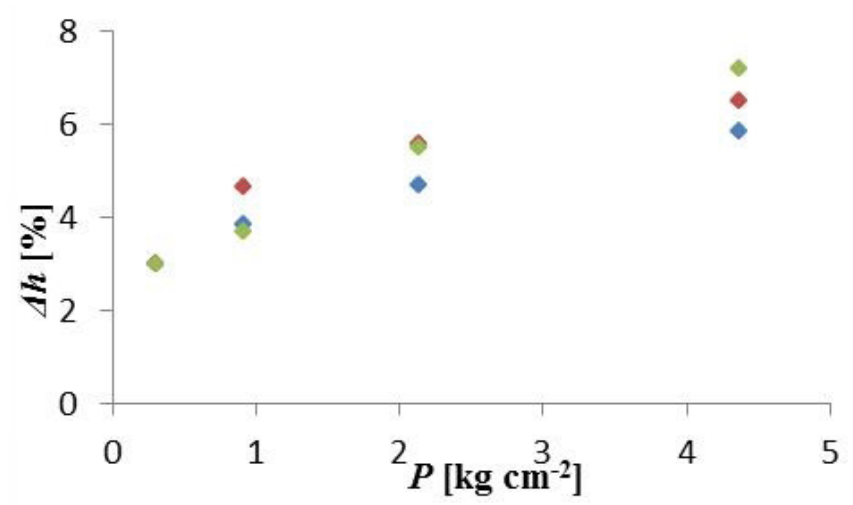

Fig. 6 Thickness change dependence of AEM on applied pressure at different temperatures $\left(\diamond 25^{\circ} \mathrm{C}, 40{ }^{\circ} \mathrm{C}, \diamond 60^{\circ} \mathrm{C}\right)$

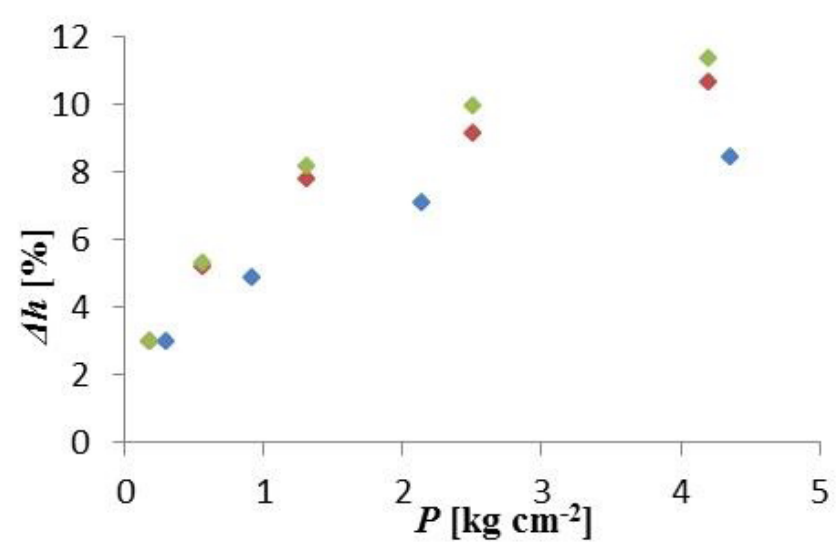

Fig. 7 Thickness change dependence of CEM on applied pressure at different temperatures $\left(\diamond 25^{\circ} \mathrm{C}, 440^{\circ} \mathrm{C}, \diamond 60^{\circ} \mathrm{C}\right)$

change was nearly the same for both foils. In the same time as in the case of ion exchange membranes (1250 hours), the foil thickness change became negligible.

\section{Conclusion}

The examination of deformation resistance of ion exchange materials and spacer frame foils used in ED and EDI devices was performed in a range of applied pressures and temperatures. The applied pressures up to $11.7 \mathrm{~kg} \mathrm{~cm}^{-2}$ and $4.36 \mathrm{~kg} \mathrm{~cm}^{-2}$ 


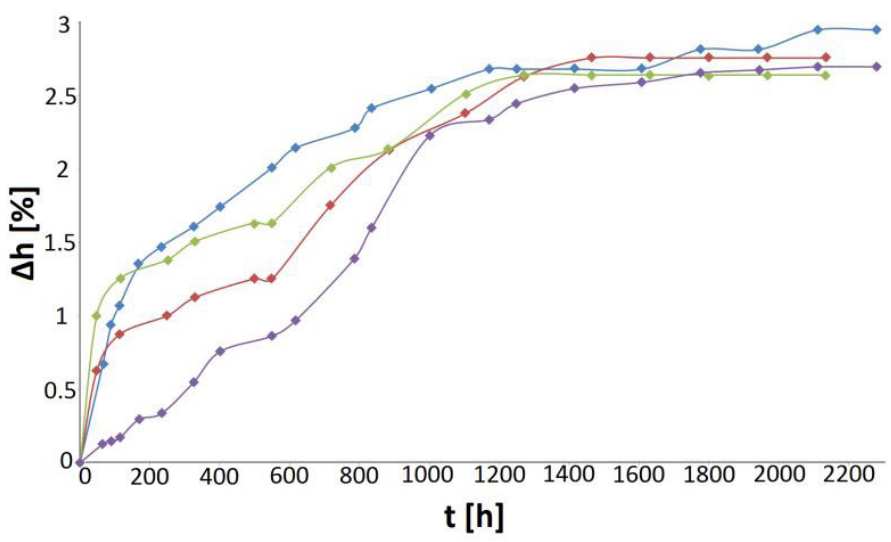

Fig. 8 Thickness changes of ion exchange membranes and spacer frame foils at constant pressure of $4.36 \mathrm{~kg} \mathrm{~cm}^{-2}$ measured in time $(\mathrm{AEM}, \mathrm{CEM}$, Bralen foil, $\bullet$ Versify ${ }^{\mathrm{TM}}$ foil)

for ion exchange resins and membranes, respectively, corresponded to the pressure to which materials are usually exposed in industrial EDI or ED stack. The results showed the strong dependence of volume changes (in case of ion exchange resins) and thickness changes (in case of ion exchange membranes) on temperature. The interesting fact regarding the mixed bed of cation and anion exchange resins Diaion $^{\mathrm{TM}}$ appeared, as the volume change of this mixture was higher than that one of pure cation or pure anion exchange resin at the same conditions. It was also shown that the macroporous resin Purolite C160 is much less deformable than the gel resin. In the case of membranes, the cation exchange membrane appeared more deformable - thickness change was $8.4 \%$ at $25{ }^{\circ} \mathrm{C}$ and $9.9 \%$ at $60{ }^{\circ} \mathrm{C}$, while the change of anion exchange membrane was only $5.9 \%$ at $25{ }^{\circ} \mathrm{C}$ and $7.9 \%$ at $60{ }^{\circ} \mathrm{C}$. However, the anion exchange membrane exhibited higher deformability in time during longterm experiment. The spacer frame foils made from Bralen and Versify ${ }^{\mathrm{TM}}$ resins in the thickness $0.8 \mathrm{~mm}$ were deformed similarly to ion exchange membranes and no significant differences were observed between these two foil kinds. Taking into account achieved results, it is clear that in the ED or EDI process, there could appear serious problems with module tightness when the temperature is changing significantly.

\section{Acknowledgement}

This work was created within the project LO1418 "Progressive Development of Membrane Innovation Center" supported by the NPU I program of the Ministry of Education, Youth and Sports of the Czech Republic using the infrastructure of the Membrane Innovation Center (No.CZ 1.05 / 2.1.00 / 03.0084).

\section{References}

[1] Strathmann, H. "Electrodialysis, a mature technology with a multitude of new applications." Desalination. 264(3), pp. 268-288. 2010. https://doi.org/10.1016/j.desal.2010.04.069

[2] Alvarado, L., Chen, A. "Electrodeionization: Principles, Strategies and Applications." Electrochimica Acta. 132, pp. 583-597. 2014. https://doi.org/10.1016/j.electacta.2014.03.165

[3] $\mathrm{Xu}, \mathrm{T}$. "Ion exchange membranes: State of their development and perspective." Journal of Membrane Science. 263(1-2), pp. 1-29. 2005. https://doi.org/10.1016/j.memsci.2005.05.002

[4] Zagorodni, A. A. "Ion exchangers, their structure and major properties." In: Ion exchange materials: Properties and applications. (pp. 9-54). 2007.

https://doi.org/10.1016/B978-008044552-6/50003-4

[5] Harland, C. E. "Properties and characterization of ion exchange resins." In: Ion Exchange: Theory and Practice: Edition 2 (pp. 49-89). 1994. https://doi.org/10.1039/9781847551184-00049

[6] Berezina, N. P., Kononenko, N. A., Dyomina, O. A., Gnusin, N. P. "Characterization of ion-exchange membrane materials: Properties vs structure." Advances in Colloid and Interface Science. 139(1), pp. 3-28. 2008. https://doi.org/10.1016/j.cis.2008.01.002

[7 Davis, T. A., Grebenyuk, V., Grebenyuk, O. "Electromembrane processes." In: Membrane Technology in the Chemical Industry (pp. 226-267). 2001. https://doi.org/10.1002/3527600388.ch12

[8] Mizutani, Y. "Structure of ion exchange membranes." Journal of Membrane Science. 49(2), pp. 121-144. 1990. https://doi.org/10.1016/S0376-7388(00)80784-X

[9] Sata, T., Tsujimoto, M., Yamaguchi, T., Matsusaki, K. "Change of anion exchange membranes in an aqueous sodium hydroxide solution at high temperature." Journal of Membrane Science. 112(2), pp. 161-170. 1996. https://doi.org/10.1016/0376-7388(95)00292-8

[10] Amel, A., Gavish, N., Zhu, L., Dekel, D. R., Hickner, M. A., Ein-Eli, Y. "Bicarbonate and chloride anion transport in anion exchange membranes." Journal of Membrane Science, 514, pp. 125-134. 2016. https://doi.org/10.1016/j.memsci.2016.04.027

[11] Lin, C. X., Zhuo, Y. Z., Hu, E. N., Zhang, Q. G., Zhu, A. M., Liu, Q. L. "Crosslinked side-chain-type anion exchange membranes with enhanced conductivity and dimensional stability." Journal of Membrane Science. 539, pp. 24-33. 2017. https://doi.org/10.1016/j.memsci.2017.05.063

[12] Laín, L., Barragán, V. M. "Swelling properties of alkali-metal doped polymeric anion-exchange membranes in alcohol media for application in fuel cells." International Journal of Hydrogen Energy. 41(32), pp. 14160-14170. 2016. https://doi.org/10.1016/j.ijhydene.2016.05.283

[13] Svoboda, M., Beneš, J., Vobecká, L., Slouka, Z. "Swelling induced structural changes of a heterogeneous cation-exchange membrane analyzed by micro-computed tomography." Journal of Membrane Science. 525, pp. 195-201. 2017. https://doi.org/10.1016/j.memsci.2016.10.046

[14] Wood, J., Gifford, J., Arba, J., Shaw, M. "Production of ultrapure water by continuous electrodeionization." Desalination. 250(3), pp. 973-976. 2010. https://doi.org/10.1016/j.desal.2009.09.084 